\title{
ANALISIS PENDAPATAN USAHATANI SAYURAN DI KECAMATAN SUMBEREJO KABUPATEN TANGGAMUS
}

(The Analysis of Income of Vegetable Farming in Sumberejo Subdistrict of Tanggamus Regency)

Namira Kinanti, Dwi Haryono, Adia Nugraha

Jurusan Agribisnis, Fakultas Pertanian, Universitas Lampung J1 Prof. Dr. SoemantriBrodjonegoro No 1 Bandar Lampung 35145, Telp. 089654338205,e-mail: namirakinanti@gmail.com

\begin{abstract}
The purposes of this research are to analyze the income of each type of vegetable farming (chilli, tomato, chicory, cucumber and cabbage), the income based on the various cropping pattern of vegetables, the cropping pattern which gives the highest income. This research was conducted with a survey method in Sumberejo Subdistrict of Tanggamus Regency and the location was selected purposively. Respondents were 53 vegetable farmers taken using Stratified Random Sampling method and determined the allocation of the proportion of the sample according to the cropping pattern. The analytical method used was farm income analysis by Rahim and Hastuti (2008). The results showed that chilli, tomato, chicory, cucumber, and cabbage farming are profitable because of the values of $R / C$ ratio $>1$. The income of vegetable farming cropping pattern 1, 2, 3 in a row are Rp203,826,644.43; Rp221,730,908.34 and Rp253,833,536.82 so that the cropping pattern that most profitable for farmers is vegetable farming cropping pattern 3 (chili-tomatocabbage) with the value of $R / C$ of 3.98 .
\end{abstract}

Key words: cropping pattern, income, vegetable farming

\section{PENDAHULUAN}

Sektor pertanian dikelompokkan menjadi beberapa subsektor yaitu subsektor tanaman pangan, hortikultura, perkebunan, perikanan, peternakan, dan kehutanan (Pusat Penelitian dan Pengembangan Hortikultura 2013). Sayuran merupakan bagian dari kelompok tanaman hortikultura berperan penting sebagai sumber vitamin, mineral, dan serat yang dibutuhkan oleh masyarakat.

Kabupaten Tanggamus merupakan salah satu sentra penghasil sayuran di Provinsi Lampung setelah Kabupaten Lampung Barat, Lampung Tengah dan Lampung Timur dengan jumlah produksi sayuran sebesar 213.360 kuintal dengan luas panen sebesar 3.786 hektar (BPS Provinsi Lampung 2014). Berdasarkan beberapa jenis sayuran yang banyak dibudidayakan, produktivitas Kabupaten Tanggamus tergolong rendah dibandingkan dengan produktivitas ratarata Provinsi Lampung. Dari 11 komoditas yang banyak ditanam, hanya tanaman terung yang memiliki produktivitas lebih tinggi dari produktivitas terung Provinsi Lampung. Rendahnya produktivitas usahatani merupakan masalah yang dihadapi petani dalam mengembangkan usahatani. Sebagian besar petani tidak dapat mengalokasikan penggunaan sumberdaya atau faktor-faktor produksi yang dimiliki secara efektif dan efisien.

Kecamatan Sumberejo memiliki luas panen dan produksi sayuran terbesar dibandingkan 19 kecamatan lain di Kabupaten Tanggamus. Produksi sayuran Kecamatan Sumberejo mampu menyumbang sebesar $38,61 \%$ dari total keseluruhan produksi sayuran Kabupaten Tanggamus (Dinas Tanaman Pangan dan Hortikultura Kabupaten Tanggamus 2014).

Hasil produksi sayuran merupakan penentu besar kecilnya pendapatan yang akan diterima petani. Luas lahan petani yang sempit mengharuskan petani melakukan perencanaan untuk memanfaatkan lahan yang dimiliki sebaik-baiknya agar memperoleh pendapatan setinggi-tingginya.

Minimnya luas lahan yang diusahakan petani disebabkan oleh beberapa hal, antara lain pembagian warisan dan alih fungsi lahan. Pola tanam merupakan hal penting yang perlu diperhatikan petani dalam melakukan usahatani. Pola tanam adalah usaha yang dilakukan dengan melaksanakan penanaman pada sebidang lahan dengan mengatur susunan tata letak dari tanaman dan tata urutan tanaman selama periode waktu tertentu, termasuk masa pengolahan tanah dan 
masa tidak ditanami selama periode tertentu (Setjanata 1983).

Mayoritas petani di Kecamatan Sumberejo melakukan usahatani dengan pola tanam monokultur serta melakukan rotasi tanaman beberapa tanaman dalam satu tahun. Pemilihan jenis tanaman yang tepat dapat memberikan beberapa keuntungan, antara lain dapat mengurangi hama dan penyakit, menambah kesuburan tanah, serta memutuskan siklus hidup hama atau penyakit. Penelitian ini bertujuan untuk menganalisis tingkat pendapatan usahatani per komoditas sayur, tingkat pendapatan usahatani sayur berdasarkan variasi pola tanam sayuran yang dilakukan dan pola tanam yang memberikan keuntungan tertinggi di Kecamatan Sumberejo Kabupaten Tanggamus

\section{METODE PENELITIAN}

Penelitian dilakukan di Desa Margodadi Kecamatan Sumberejo, Kabupaten Tanggamus. Penentuan lokasi penelitian dilakukan secara sengaja (purposive) karena produktivitas komoditas sayuran di Kabupaten Tanggamus masih terbilang rendah dan potensinya harus dikembangkan. Kecamatan Sumberejo memiliki produksi sayuran tertinggi di Kabupaten Tanggamus. Pemilihan Desa Margodadi berdasarkan pertimbangan informasi dari Balai Penyuluhan Pertanian, Perikanan dan Kehutanan (BP3K) Kecamatan Sumberejo bahwa Desa Margodadi merupakan salah satu desa penghasil utama sayuran di Kecamatan Sumberejo. Faktor lain dalam memilih Desa Margodadi sebagai lokasi penelitian adalah karena desa ini memiliki potensi untuk menjadi sentra produksi sayuran.

Terdapat tiga pola rotasi tanaman yang mayoritas diterapkan petani berdasarkan komoditaskomoditas yang banyak ditanam petani di lokasi penelitiaan. Pola tanam 1 (PT 1) yaitu cabaitomat-sawi, PT 2 yaitu cabai-tomat-mentimun, dan PT 3 yaitu cabai-tomat-kubis. Populasi petani Desa Margodadi tersebut bersifat heterogen, yaitu terdapat perbedaan dalam pola tanam komoditas sayuran yang dibudidayakan. Untuk dapat menggambarkan secara tepat mengenai sifat-sifat populasi yang heterogen, maka penentuan sampel dilakukan dengan metode stratified random sampling. Populasi petani dibagi-bagi berdasarkan populasi yang seragam dan dari setiap populasi dapat diambil sampel secara acak.
Populasi petani sayur di Desa Margodadi sebanyak 173 orang dari total keseluruhan jumlah petani, yang terdiri dari petani pola tanam 1 adalah 58 orang, petani PT 2 adalah 65 orang, dan petani PT 3 adalah 50 orang. Jumlah populasi petani maka selanjutnya ditentukan jumlah sampel dengan menggunakan rumus yang merujuk pada Issac dan Michael dalam Sugiarto (2003) yaitu:

$$
\mathrm{n}=\frac{\mathrm{NZ}^{2} \mathrm{~S}^{2}}{\mathrm{Nd}^{2}+\mathrm{Z}^{2} \mathrm{~S}^{2}}
$$

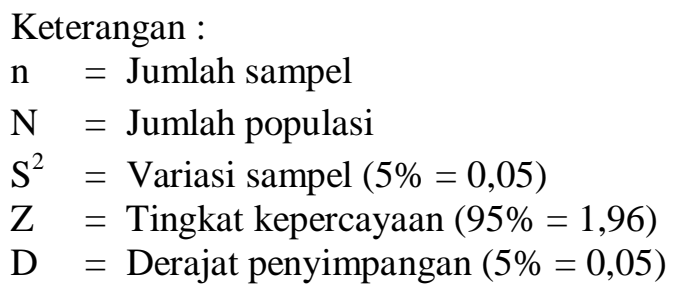

Berdasarkan persamaan di atas, diperoleh jumlah responden sebanyak 53 orang, kemudian dari jumlah tersebut ditentukan alokasi proporsi sampel tiap pola rotasi dengan rumus :

$\mathrm{n}_{\mathrm{i}}=\frac{\mathrm{N}_{\mathrm{i}}}{\mathrm{N}} \times \mathrm{n}$

Keterangan:

ni = Jumlah sampel

$\mathrm{Ni}=$ Jumlah anggota

$\mathrm{N}=$ Jumlah anggota dalam populasi

$\mathrm{n}$ = Jumlah sampel

Setelah didapat jumlah sampel dari masingmasing populasi, maka dibuatlah kerangka sampling untuk setiap populasi, kemudian sampel diambil secara acak. Penggunaan metode ini berarti masing-masing populasi dapat terwakili. Waktu pengambilan data yaitu Bulan OktoberDesember 2016.

Data yang digunakan dalam penelitian ini terdiri dari data primer dan data sekunder. Data primer diperoleh dari data usahatani yang dilakukan petani dalam satu tahun. Teknik pengumpulan data primer diperoleh melalui wawancara langsung dengan petani responden menggunakan alat bantu kuesioner (daftar pertanyaan). Data sekunder merupakan data penunjang dari data primer yang diperoleh dari literatur, laporan, studi kepustakaan, serta instansi atau lembaga yang berkaitan dengan penelitian antara lain Badan Pusat Statistik, Dinas Tanaman Pangan dan Hortikultura, Balai Penyuluhan Pertanian, Perikanan, dan Kehutanan (BP3K). 
Metode analisis data yang digunakan adalah analisis kuantitatif dan kualitatif. Metode analisis kuantitatif digunakan untuk menganalisi tingkat keuntungan usahatani. Analisis data kualitatif dilakukan secara deskriptif untuk menjabarkan hasil dari ketiga tujuan dalam penelitian.

Analisis pendapatan usahatani pola rotasi dilakukan dengan mencari selisih antara penerimaan dan pengeluaran usahatani dari setiap jenis tanaman yang diusahakan. Kondisi pendapatan usahatani diharapkan bernilai positif. Pendapatan usahatani dapat dirumuskan sebagai berikut (Rahim dan Hastuti 2008) :

$$
\begin{aligned}
\mathrm{Pd} & =\mathrm{TR}-\mathrm{TC} \\
& =\mathrm{Y} . P y-\mathrm{VC}-\mathrm{FC} \\
& =\mathrm{Y} . P y-\sum X i . P x i-\mathrm{FC}
\end{aligned}
$$

Keterangan :

$$
\begin{aligned}
\mathrm{Pd}= & \text { Pendapatan usahatani }(\mathrm{Rp} / \text { musim tanam }) \\
\mathrm{TR}= & \text { Penerimaan total }(\text { total revenue }) \\
& (\mathrm{Rp} / \text { musim tanam }) \\
\mathrm{TC}= & \text { Biaya total }(\text { total cost })(\mathrm{Rp} / \text { musim tanam }) \\
\mathrm{Y}= & \text { Hasil produksi }(\mathrm{Kg}) \\
\mathrm{Py}= & \text { Harga hasil produksi }(\mathrm{Rp}) \\
\mathrm{Xi}= & \text { Faktor produksi variabel }(\mathrm{i}=1,2,3, \ldots, \mathrm{n}) \\
\mathrm{Pxi}= & \text { Harga faktor produksi variabel ke-i }(\mathrm{Rp}) \\
\mathrm{FC}= & \text { Biaya tetap }(\text { fixed cost })(\mathrm{Rp}) \\
\mathrm{VC}= & \text { Biaya variabel }(\text { variable cost })(\mathrm{Rp})
\end{aligned}
$$

Efisiensi usahatani digambarkan oleh nilai imbangan antara jumlah penerimaan dengan biaya. Analisis efisiensi yang digunakan adalah rasio $\mathrm{R} / \mathrm{C}$ atas biaya tunai dan $\mathrm{R} / \mathrm{C}$ atas biaya total. Rasio R/C secara matematis dapat dituliskan sebagai berikut :

$$
\mathrm{R} / \mathrm{C} \text { ratio }=\frac{\mathrm{TR}}{\mathrm{TC}}
$$

Keterangan :

$\mathrm{TR}=$ Penerimaan total (totalrevenue)

$\mathrm{TC}=$ Biaya total (total cost)

Kriteria efisiensi usahatani :

$\mathrm{R} / \mathrm{C}>1$, usahatani menguntungkan

$\mathrm{R} / \mathrm{C}<1$, usahatani merugi

$\mathrm{R} / \mathrm{C}=1$, usahatani impas (tidak untung/tidak rugi)

\section{HASIL PENELITIAN DAN PEMBAHASAN}

\section{Keadaan Umum Responden}

Rata-rata umur petani responden adalah 44,45 tahun, hal ini menunjukkan bahwa petani tergolong berusia produktif (Mantra 2004). Pada usia produktif, petani mempunyai kemampuan yang besar dalam menyerap informasi dan teknologi yang inovatif di bidang pertanian, sehingga dapat menambah keterampilan dalam berusahatani yang dapat meningkatkan hasil produksi dan keuntungan (Subagio dan Manoppo 2011). Rata-rata tingkat pendidikan petani adalah tingkat menengah atau SMP, rata-rata pengalaman berusahatani petani adalah 17 tahun, rata-rata jumlah tanggungan keluarga 3 orang. Pola kepemilikan lahan petani responden diantaranya pemilik lahan dan penyewa lahan dengan presentase pemilik sebesar $73,58 \%$, dan penyewa sebesar $26,42 \%$.

\section{Keragaan Usahatani di Desa Margodadi}

Petani Desa Margodadi Kecamatan Sumberejo mayoritas menjadikan komoditas hortikultura sayuran sebagai komoditas utama. Sayuran diusahakan oleh petani ditanam di lahan sawah, Jenis sayuran yang ditanam adalah Cabai Merah (Capsicum annum), Tomat (Solanum lycopersicum L), Sawi (Brassica sinensis L), Mentimun (Cucumis sativus L), dan Kubis (Brassica oleracea L). Tanaman sayuranyang diusahakan petani bersifat semusim dengan umur relatif pendek, ditanam secara monokultur dan di tanam secara bergulir (rotasi) selama satu tahun atau tiga musim tanam. Rata-rata luas lahan garapan petani responden yang menerapkan pola tanam 1 adalah 0,18 ha, pola tanam 2 adalah 0,20 ha, dan pola tanam 3 adalah 0,22 ha. Pola tanam usahatani yang diterapkan petani di lokasi penelitian dapat dilihat pada Gambar 1, 2 dan 3 .

\section{Penggunaan Sarana Produksi}

Proses produksi usahatani sayuran di lokasi penelitian menggunakan sarana produksi seperti benih, pupuk (Urea, NPK Bass, SP-36, KCl, Phonska, kandang, ZA, dan mikrosil), pestisida, dan irigasi. Benih yang digunakan oleh petani yaitu cabai bermerek Lado F1, tomat bermerek Timoti, sawi bermerek Sakata, mentimun bermerek Harmony, dan kubis bermerek Grand 22. 


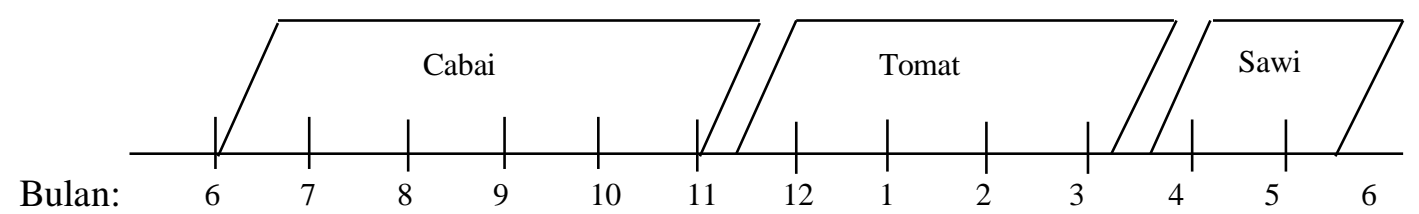

Gambar 1. Pola tanam 1 di Desa Margodadi Kecamatan Sumberejo

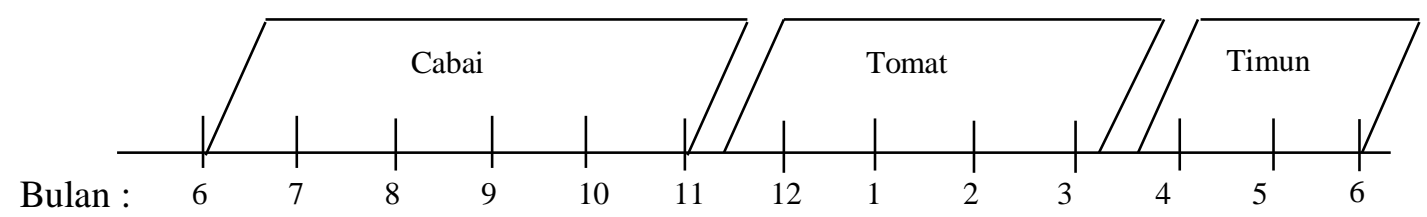

Gambar 2. Pola tanam 2 di Desa Margodadi Kecamatan Sumberejo

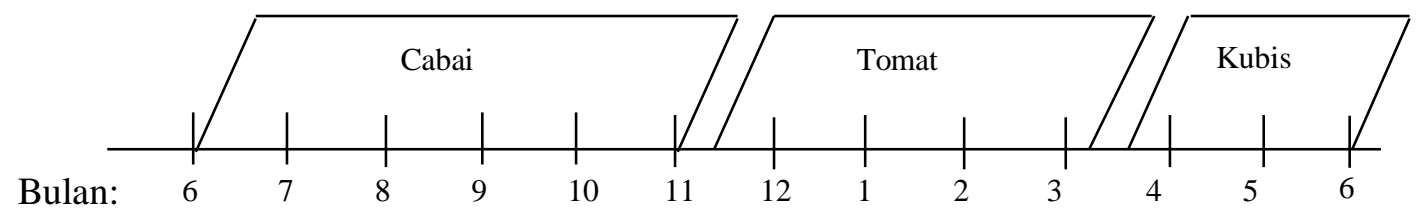

Gambar 3. Pola tanam 3 di Desa Margodadi Kecamatan Sumberejo

Penggunaan pestisida berjenis insektisida dengan merek Demolish 18 EC, Virtako, Regent, Biocron, Curacron, Prevathon, Winder, pestisida berjenis fungisida bermerek Antracol, Amistartop, Dithane, Bendas, Festans, Ziflo, Wendry, herbisida bermerek Gramoxone, serta zat tumbuh tanaman yaitu kalsium dan gandasil B. Input-input tersebut diperoleh dari kios pertanian yang ada di desa maupun kios pasar terdekat dari desa. Penggunaan sarana produksi per usahatani dapat dilihat pada Tabel 1. Pada usahatani tomat dan mentimun, petani hanya menggunakan pupuk NPK Bass, hal ini dikarenakan pada saat melakukan perguliran tanaman dari cabai ke usahatani tomat lalu usahatani mentimun, petani tidak melakukan olah lahan lagi, dan tidak melepas mulsa yang ada sehingga tidak diberikan pupuk dasar seperti saat awal menanam cabai dan selama musim tanam petani hanya mengocor tanaman dengan pupuk NPK Bass. Untuk usahatani sawi dan kubis yang ditanam pada saat musim tanam ketiga, petani melepas mulsa dan melakukan olah lahan namun lahan hanya dicangkul tanpa melakukan pembajakan lagi sehingga pupuk yang digunakan tak sebanyak awal tanam pada saat musim tanam pertama.

Tabel 1. Rata-rata penggunaan sarana produksi masing-masing usahatani per pola tanam di Kecamatan Sumberejo Kabupaten Tanggamus per hektar

\begin{tabular}{llccccccccc}
\hline \multirow{2}{*}{ No } & \multirow{2}{*}{ Jenis Sarana Produksi } & \multicolumn{3}{c}{ PT 1 } & \multicolumn{3}{c}{ PT 2 } & \multicolumn{3}{c}{ PT 3 } \\
\cline { 2 - 9 } & Cabai & Tomat & Sawi & Cabai & Tomat & Mentimun & Cabai & Tomat & Kubis \\
\hline 1 & Benih (gram) & 146,61 & 92,59 & 212,94 & 146,25 & 96,25 & 362,50 & 130,32 & 89,39 & 213,64 \\
2 & Pupuk Urea (kg) & 395,28 & - & - & 246,90 & - & - & 223,50 & - & - \\
3 & Pupuk NPK Bass (kg) & 267,00 & 280,89 & 212,94 & 258,75 & 241,25 & 258,75 & 236,36 & 225,77 & 210,59 \\
4 & Pupuk SP-36 & 400,00 & - & - & 400,00 & - & - & 400,95 & - & - \\
5 & Pupuk KCl & 129,61 & - & - & 95,00 & - & - & 121,23 & - & - \\
6 & Pupuk Phonska & 369,28 & - & - & 384,70 & - & - & 392,41 & - & - \\
7 & Pupuk Kandang & 5162,06 & - & $4.043,22$ & 5477,25 & - & - & $6.489,91$ & - & $3.803,05$ \\
8 & Pupuk ZA & 379,11 & - & 321,00 & 400,00 & - & - & 360,14 & - & 312,14 \\
9 & Mikrosil & 8,33 & - & - & 17,85 & - & - & 21,23 & - & - \\
\hline
\end{tabular}




\section{Penggunaan Tenaga Kerja}

Tenaga kerja di lokasi penelitian berasal dari dalam maupun luar keluarga petani. Upah tenaga kerja laki-laki maupun perempuan di lokasi penelitian adalah sama yaitu berkisar Rp40.000,00-Rp50.000,00. Curahan tenaga kerja pada kegiatan usahatani sayuran dibagi ke dalam beberapa kelompok kegiatan-kegiatan produksi yaitu penyemaian, pengolahan lahan dan pembuatan bedengan, pemasangan dan pelubangan mulsa, pemasangan ajir, penanaman, pemupukan, penyulaman, pengendalian HPT, pembersihan gulma dan pemanenan.

Tabel 2 menunjukkan total tenaga kerja yang digunakan setiap kegiatan usahatani pada masingmasing pola tanam. Usahatani cabai merupakan usahatani dengan total Hari Orang Kerja (HOK) terbesar, karena cabai adalah tanaman yang ditanam pada musim tanam pertama, sehingga petani perlu melakukan seluruh proses kegiatan dari awal penyemaian sampai pemanenan, sedangkan untuk usahatani tomat, petani tidak melakukan kegiatan 2 dan 3, hal ini karena tomat yang ditanam pada musim tanam kedua setelah cabai, sehingga mulsa yang sudah ada tidak dilepas kembali dan petani tidak melakukan pengolahan lahan dan pembuatan bedengan serta pemasangan dan pelubangan mulsa kembali.

Untuk usahatani mentimun sama halnya dengan usahatani tomat, namun mentimun tidak perlu melakukan penyemaian terlebih dahulu. Untuk usahatani sawi dan kubis yang ditanam pada musim tanam ketiga, tidak ada tenaga kerja untuk kegiatan 3 dan 4 karena dalam budidaya sawi dan kubis, petani tidak menggunakan mulsa dan ajir, sehingga total HOK pada usahatani sawi dan kubis lebih kecil dibanding usahatani lainnya. Tenaga kerja pada masing-masing usahatani paling banyak dicurahkan untuk kegiatan pengolahan lahan dan pembuatan bedengan serta proses pemanenan.

\section{Penggunaan Alat-Alat Pertanian}

Setiap peralatan pertanian memiliki harga dan umur ekonomis yang berbeda. Nilai harga dan umur ekonomis ini kemudian digunakan untuk menghitung biaya penyusutan dari masing-masing alat tersebut dalam satu kali musim tanam. Alatalat pertanian yang digunakan dalam proses produksi usahatani cabai, tomat dan mentimun adalah cangkul, arit, mulsa, ajir, sprayer, golok, tali rafia, dan ember, sedangkan alat-alat pertanian yang digunakan dalam proses produksi usahatani sawi dan kubis lebih sedikit yaitu hanya cangkul, arit, sprayer, golok, dan ember. Nilai penyusutan peralatan per rata-rata luas lahan garapan dalam kegiatan usahatani pada pola tanam 1 yaitu cabai dan tomat sebesar Rp800.782,45/musim tanam, usahatani sawi sebesar Rp50.506,52/musim tanam, usahatani pola tanam 2 yaitu cabai, tomat, dan mentimun sebesar Rp1.003.333,36/musim tanam, dan usahatani pola tanam 3 yaitu cabai dan tomat sebesar Rp1.028.062,23/musim tanam, usahatani kubis sebesar Rp44.706,67/musim tanam.

\section{Produksi Usahatani Sayuran}

Produksi usahatani sayuran merupakan hasil dari usahatani sayuran (cabai, tomat, sawi, mentimun dan kubis) yang didapatkan oleh petani dalam satu periode tanam.

Tabel 2. Rata-rata penggunaan tenaga kerja masing-masing usahatani per pola tanam di Kecamatan Sumberejo Kabupaten Tanggamus per hektar (HOK/ha)

\begin{tabular}{|c|c|c|c|c|c|c|c|c|c|c|}
\hline \multirow{2}{*}{ No } & \multirow{2}{*}{ Kegiatan } & \multicolumn{3}{|c|}{ PT 1} & \multicolumn{3}{|c|}{ PT 2} & \multicolumn{3}{|c|}{ PT 3} \\
\hline & & Cabai & Tomat & Sawi & Cabai & Tomat & Mentimun & Cabai & Tomat & Kubis \\
\hline 1 & Penyemaian & 4,56 & 4,56 & 4,56 & 3,70 & 3,70 & - & 4,50 & 4,50 & 5,50 \\
\hline 2 & Pengolahan lahan dan pembuatan bedengan & 84,83 & - & 30,94 & 112,95 & - & - & 138,41 & - & 40,39 \\
\hline 3 & Pemasangan dan pelubangan mulsa & 21,78 & - & - & 27,90 & - & - & 22,73 & - & - \\
\hline 4 & Pemasangan ajir & 21,94 & 20,44 & - & 31,00 & 23,75 & 26,25 & 20,91 & 24,23 & - \\
\hline 5 & Penanaman & 10,72 & 10,72 & 10,44 & 13,25 & 13,25 & 13,25 & 13,23 & 13,23 & 16,17 \\
\hline 6 & Pemupukan & 37,78 & 26,83 & 24,06 & 48,15 & 30,60 & 26,70 & 37,18 & 27,09 & 27,50 \\
\hline 7 & Penyulaman & 2,22 & 1,56 & 1,78 & 2,35 & 1,40 & 2,90 & 2,00 & 1,82 & 3,06 \\
\hline 8 & Pengendalian HPT & 20,06 & 19,11 & 13,72 & 24,15 & 18,50 & 18,45 & 31,00 & 20,55 & 20,06 \\
\hline 9 & Pembersihan gulma & 35,44 & 28,22 & 29,72 & 43,05 & 28,35 & 29,75 & 59,45 & 31,50 & 37,00 \\
\hline 10 & Pemanenan & 133,78 & 89,72 & 13,33 & 123,60 & 91,60 & 100,45 & 122,82 & 85,91 & 12,61 \\
\hline & Total & 373,11 & 201,17 & 128,56 & 430,10 & 211,15 & 217,75 & 452,23 & 208,82 & 162,28 \\
\hline
\end{tabular}


Tabel 3. Produksi dan harga komoditas sayuran pada masing-masing pola tanam

\begin{tabular}{ccc}
\hline $\begin{array}{c}\text { Pola } \\
\text { Tanam }\end{array}$ & $\begin{array}{c}\text { Produksi } \\
\mathrm{kg} / \mathrm{ha}\end{array}$ & $\begin{array}{c}\text { Harga } \\
\mathrm{Rp} / \mathrm{kg}\end{array}$ \\
\hline PT 1 & & \\
Cabai & $11.373,44$ & $15.033,25$ \\
Tomat & $28.302,44$ & $2.712,33$ \\
Sawi & $25.771,61$ & $1.463,89$ \\
\hline PT 2 & & \\
Cabai & $11.900,00$ & $15.028,31$ \\
Tomat & $29.012,50$ & $2.719,67$ \\
Mentimun & $30.605,00$ & $1.863,92$ \\
\hline PT 3 & & \\
Cabai & $11.189,09$ & $15.046,62$ \\
Tomat & $28.748,50$ & $2.731,40$ \\
Kubis & $32.090,91$ & $2.866,67$ \\
\hline
\end{tabular}

Produksi sayuran yang diperoleh setiap petani berbeda-beda, tergantung pada luas lahan yang mereka miliki dan perawatan yang dilakukan. Produksi dan harga komoditas sayuran disajikan pada Tabel 3.

Produksi cabai rata-rata dari ketiga pola tanam adalah $11.487,51 \mathrm{~kg} / \mathrm{ha}$ per musim tanam, petani cabai pada pola tanam 2 menghasilkan produksi cabai yang paling tinggi yaitu sebesar 11.900 $\mathrm{kg} / \mathrm{ha}$ per musim tanam. Produksi tomat rata-rata dari ketiga pola tanam adalah $28.687,85 \mathrm{~kg} / \mathrm{ha}$ per musim tanam, produksi tomat yang paling tinggi adalah petani pada pola tanam 2 dengan produksi sebesar $29.012,50 \mathrm{~kg} / \mathrm{ha}$ per musim tanam.

Untuk musim tanam 3, kubis menghasilkan produksi yang lebih tinggi dibandingkan dengan produksi sawi dan mentimun yaitu sebesar $32.090,91 \mathrm{~kg} / \mathrm{ha}$ per musim tanam. Harga rata-rata komoditas sayuran yang sama pada masingmasing pola tanam tidak jauh berbeda, untuk komoditas cabai harga rata-rata yang diterima petani adalah $\mathrm{Rp} 15.000,00 / \mathrm{kg}$ dan untuk tomat adalah Rp2.700,00/kg.

\section{Pendapatan Usahatani Sayuran}

Pendapatan usahatani sayuran merupakan pengurangan antara penerimaan dan biaya produksi. Biaya produksi yang digunakan dalam usahatani terdiri dari biaya tunai dan biaya diperhitungkan. Semua biaya yang digunakan dihitung dalam satu periode musim tanam per satu hektar. Rincian penerimaan, biaya dan pendapatan masing-masing usahatani disajikan pada Tabel 4.
Tabel 4 menunjukkan bahwa penerimaan yang paling besar di setiap pola tanam adalah cabai, hal ini dipengaruhi oleh harga cabai yang lebih tinggi dibandingkan harga komoditas sayuran yang lainnya, sedangkan penerimaan usahatani terendah adalah usahatani sawi. Biaya tunai meliputi biaya benih, biaya pupuk, biaya pestisida, biaya tenaga kerja luar keluarga (TKLK), iuran irigasi, biaya angkut dan biaya pajak. Biaya tunai usahatani cabai yang dikeluarkan oleh petani lebih besar karena penggunaan pupuk dan pestisida pada usahatani cabai lebih banyak dari usahatani lainnya. Biaya diperhitungkan meliputi biaya sewa lahan, biaya penyusutan alat pertanian dan biaya tenaga kerja dalam keluarga (TKDK). Penggunaan mulsa dan ajir pada saat menanam cabai, tomat dan mentimun menyebabkan nilai penyusutan alat pertanian ketiga usahatani tersebut lebih besar dari usahatani sawi dan kubis sehingga mempengaruhi besarnya total biaya diperhitungkan.

$\mathrm{R} / \mathrm{C}$ rasio atas biaya tunai dan total usahatani cabai PT 1, 2, dan 3 adalah sebesar 7,97; 7,24; 7,19 dan 4,57; 4,48; 4,19. Nilai R/C rasio lebih dari 1 menunjukkan bahwa usahatani cabai menguntungkan dan setiap penambahan Rp1,00 biaya tunai maupun total yang dikeluarkan akan menghasilkan penerimaan sebesar Rp7,97; $\mathrm{Rp7,24;} \mathrm{Rp7,19}$ atas biaya tunai dan $\mathrm{Rp} 4,57$; Rp4,48; Rp4,19 atas biaya total.

$\mathrm{R} / \mathrm{C}$ rasio atas biaya tunai dan total usahatani tomat PT 1, 2, dan 3 adalah sebesar 5,69; 5,30; 5,43 dan 2,$88 ; 2,95 ; 2,97$. Nilai $\mathrm{R} / \mathrm{C}$ rasio lebih dari 1 menunjukkan bahwa usahatani tomat menguntungkan dan setiap penambahan $\mathrm{Rp} 1,00$ biaya tunai maupun total yang dikeluarkan akan menghasilkan penerimaan sebesar Rp5,69; $\mathrm{Rp5}, 30$; $\mathrm{Rp} 5,43$ atas biaya tunai dan $\mathrm{Rp} 2,88$; Rp2,95; Rp2,97 atas biaya total. Nilai R/C usahatani tomat yang diperoleh oleh penelitian ini lebih kecil dibandingkan dengan penelitian Heriani, Zakaria, Soelaiman (2013) yang menyatakan bahwa $\mathrm{R} / \mathrm{C}$ usahatani tomat di daerah penelitian sebesar 3,03. Perbedaan hasil ini disebabkan oleh jumlah produksi tomat petani pada penelitian ini lebih rendah dan total biaya yang dikeluarkan petani lebih besar dibandingkan pada penelitian Heriani, Zakaria, dan Soelaiman (2013). 


\section{JIIA, VOLUME 6 No. 4, NOVEMBER 2018}

Tabel 4. Rata-rata penerimaan, biaya, dan pendapatan masing-masing usahatani sayuran per hektar

\begin{tabular}{|c|c|c|c|c|c|c|c|c|}
\hline \multirow[b]{2}{*}{$\begin{array}{l}\text { Pola } \\
\text { Tanam }\end{array}$} & \multirow[b]{2}{*}{ Penerimaan } & \multicolumn{3}{|c|}{ Biaya } & \multicolumn{2}{|c|}{ Pendapatan Atas } & \multicolumn{2}{|c|}{$\mathrm{R} / \mathrm{C}$} \\
\hline & & Tunai & Diperhitungkan & Total & $\begin{array}{l}\text { Biaya } \\
\text { Tunai }\end{array}$ & $\begin{array}{c}\text { Biaya } \\
\text { Total }\end{array}$ & $\begin{array}{l}\text { Biaya } \\
\text { Tunai }\end{array}$ & $\begin{array}{l}\text { Biaya } \\
\text { Total }\end{array}$ \\
\hline \multicolumn{9}{|l|}{ PT 1} \\
\hline Cabai & $170.980 .009,72$ & $21.455 .404,87$ & $15.981 .713,73$ & $37.437 .118,60$ & $149.524 .604,84$ & $133.542 .891,11$ & 7,97 & 4,57 \\
\hline Tomat & 76.765.767,89 & $13.494 .399,86$ & $13.199 .477,79$ & $26.693 .877,65$ & $63.271 .368,03$ & $50.071 .890,24$ & 5,69 & 2,88 \\
\hline Sawi & $37.726 .766,12$ & $9.696 .632,37$ & 7.818.270,66 & $17.514 .903,03$ & $28.030 .133,74$ & $20.211 .863,09$ & 3,89 & 2,15 \\
\hline Total & $285.472 .543,72$ & $44.646 .437,10$ & $36.999 .462,18$ & $81.645 .899,29$ & $240.826 .106,62$ & $203.826 .644,43$ & 6,39 & 3,50 \\
\hline \multicolumn{9}{|c|}{ (1) } \\
\hline Cabai & $178.836 .866,16$ & $24.710 .818,87$ & $15.188 .514,33$ & $39.899 .333,20$ & $154.126 .047,29$ & $138.937 .532,96$ & 7,24 & 4,48 \\
\hline Tomat & $78.904 .501,86$ & $14.886 .768,75$ & $11.901 .545,58$ & $26.788 .314,33$ & $64.017 .733,11$ & $52.116 .187,53$ & 5,30 & 2,95 \\
\hline Mentimun & $57.045 .230,31$ & $14.656 .809,38$ & $11.711 .233,08$ & $26.368 .042,46$ & $42.388 .420,93$ & $30.677 .187,85$ & 3,89 & 2,16 \\
\hline Total & $314.786 .598,33$ & $54.245 .397,00$ & $38.801 .292,99$ & $93.055 .689,99$ & $260.532 .201,34$ & $221.730 .908,34$ & 5,80 & 3,38 \\
\hline \multicolumn{9}{|l|}{ PT 3} \\
\hline Cabai & $168.357 .956,11$ & $23.425 .142,37$ & $16.710 .838,39$ & $40.135 .980,76$ & $144.932 .813,73$ & $128.221 .975,34$ & 7,19 & 4,19 \\
\hline Tomat & $78.523 .672,36$ & $14.463 .868,69$ & $11.930 .888,89$ & $26.394,757,58$ & $64.059 .803,67$ & $52.128 .914,78$ & 5,43 & 2,97 \\
\hline Kubis & $91.993 .939,39$ & $11.778 .232,09$ & $6.733 .060,61$ & $18.511 .292,70$ & $80.215 .707,31$ & $73.482 .646,70$ & 7,81 & 4,97 \\
\hline Total & $338.875 .567,86$ & $49.667 .243,15$ & $35.374 .787,89$ & $85.042 .031,04$ & $289.208 .324,71$ & $253.833 .536,82$ & 6,82 & 3,98 \\
\hline
\end{tabular}

$\mathrm{R} / \mathrm{C}$ rasio atas biaya tunai dan total usahatani sawi pada PT 1 adalah sebesar 3,89 dan 2,15. Nilai $\mathrm{R} / \mathrm{C}$ rasio lebih dari 1 menunjukkan bahwa usahatani sawi menguntungkan dan setiap penambahan Rp1,00 biaya tunai maupun total yang dikeluarkan akan menghasilkan penerimaan sebesar Rp3,89 atas biaya tunai dan Rp2,15 atas biaya total.

$\mathrm{R} / \mathrm{C}$ rasio atas biaya tunai dan total usahatani mentimun pada PT 2 adalah sebesar 3,89 dan 2,16. Nilai $\mathrm{R} / \mathrm{C}$ rasio lebih dari 1 menunjukkan bahwa usahatani mentimun menguntungkan dan setiap penambahan Rp1,00 biaya tunai maupun total yang dikeluarkan akan menghasilkan penerimaan sebesar Rp3,89 atas biaya tunai dan $\mathrm{Rp} 2,16$ atas biaya total.

$\mathrm{R} / \mathrm{C}$ rasio atas biaya tunai dan total usahatani kubis pada PT 3 adalah sebesar 7,81 dan 4,97. Nilai R/C rasio lebih dari 1 menunjukkan bahwa usahatani kubis menguntungkan dan setiap penambahan Rp1,00 biaya tunai maupun total yang dikeluarkan akan menghasilkan penerimaan sebesar Rp7,81 atas biaya tunai dan 4,97 atas biaya total. Pendapatan kubis yang diperoleh petani pada penelitian ini lebih besar dibandingkan dengan penelitian yang dilakukan oleh Aini, Prasmatiwi, Sayekti (2015). Hal ini karena produktivitas tanaman kubis di lokasi penelitian lebih tinggi yaitu sebesar 32,09 ton/ha sedangkan pada penelitian Aini, Prasmatiwi, dan Sayekti (2015) produktivitasnya sebesar 15,09 ton/ha untuk tanaman kubis lahan kering, dan 22,09 ton/ha untuk tanaman kubis lahan sawah tadah hujan. Mujiburrahmad (2011) menyatakan bahwa besarnya pendapatan yang diperoleh oleh petani akan berbanding lurus dengan produktivitasnya, dimana semakin tinggi produktivitas suatu lahan, maka semakin besar pendapatan yang mungkin diperoleh petani.

Analisis pendapatan usahatani sayuran pada penelitian ini menunjukkan bahwa pendapatan pada usahatani cabai adalah pendapatan yang terbesar, hal ini sejalan dengan penelitian yang dilakukan oleh Khoirunnisa, Haryono, dan Nugraha (2013) yang menyatakan bahwa pendapatan usahatani cabai lebih besar dibandingkan usahatani sawi, terung, tomat, dan mentimun.

Petani di lokasi penelitian menerapkan pola rotasi tanaman dalam satu tahun atau tiga musim tanam dalam satu tahun. Pendapatan usahatani satu tahun ini dihitung berdasarkan akumulasi dari biaya dan penerimaan masing-masing ketiga usahatani yang diusahakan oleh petani dalam satu tahun per satu hektar seperti disajikan pada Tabel 4. Penerimaan usahatani pola tanam cabai-tomatkubis (PT3) lebih tinggi jika dibandingkan dengan usahatani lainnya yaitu dengan penerimaan sebesar Rp338.875.567,86 per hektar, diikuti dengan pola tanam 2 , lalu pola tanam 1 . Hal ini dipengaruhi oleh jumlah produksi dan harga kubis yang lebih tinggi dibandingkan pada usahatani sawi dan mentimun. Untuk total biaya produksi usahatani, PT 2 lebih besar dari usahatani lainnya yaitu sebesar Rp93.055.689,99, diikuti PT 3 dan PT 1. Pendapatan atas biaya total usahatani sayuran dari yang tertinggi ke terendah yaitu pendapatan usahatani PT 3, PT 2, dan PT1.

Pendapatan usahatani dari setiap pola tanam yang diterapkan oleh petani kemudian dibandingkan 
berdasarkan $\mathrm{R} / \mathrm{C}$ rasio atas biaya total sehingga menguntungkan petani. $\mathrm{R} / \mathrm{C}$ rasio yang paling besar adalah $\mathrm{R} / \mathrm{C}$ rasio dari pola tanam ketiga yaitu cabai-tomat-kubis sebesar 3,98. Itu berarti pola tanam cabai-tomat-kubis adalah yang paling menguntungkan, diikuti pola tanam satu yaitu cabai-tomat-sawi, lalu pola tanam dua, cabaitomat-mentimun.

\section{KESIMPULAN}

Berdasarkan hasil penelitian yang telah dilakukan maka dapat disimpulkan bahwa masing-masing usahatani cabai, tomat, sawi, mentimun, dan kubis menguntungkan untuk diusahakan karena memiliki nilai R/C rasio lebih dari 1. Pendapatan usahatani sayuran PT 1, 2 dan 3 yaitu sebesar Rp203.826.644,43; Rp221.730.908,34 dan Rp253.833.536,82, sehingga pola tanam sayuran yang paling menguntungkan petani adalah pola tanam 3 (cabai-tomat-kubis) dengan nilai $\mathrm{R} / \mathrm{C}$ sebesar 3,98.

\section{DAFTAR PUSTAKA}

Aini HN, Prasmatiwi FE, dan Sayekti WD. 2015. Analisis pendapatan dan risiko usahatani kubis pada lahan kering dan lahan sawah tadah hujan di Kecamatan Gisting Kabupaten Tanggamus. Jurnal Ilmu-Ilmu Agribisnis, 3 (1): 1-9. http:// jurnal.fp. unila.ac.id/index.php/JIA/article/view/1011 1916.[27 Maret 2018]

BPS Provinsi Lampung. 2014. Lampung dalam Angka. BPS Provinsi Lampung. Lampung.

Dinas Tanaman Pangan dan Hortikultura Kabupaten Tanggamus. 2014. Angka Perhitungan Dinas Tahun 2013. Dinas Tanaman Pangan dan Hortikultura Kabupaten Tanggamus. Lampung.

Heriani N, Zakaria W A, dan Soelaiman A. 2013. Analisis Keuntungan dan Risiko Usahatani Tomat di Kecamatan Sumberejo Kabupaten Tanggamus. Jurnal Ilmu-Ilmu Agribisnis, dapat diketahui pola tanam yang paling 1 (2): 169-173.http://jurnal.fp.unila.ac.id/ index.php/JIA/article/view/244/243. Maret 2018].

Khoirunnisa A, Haryono D, dan Nugraha A. 2013. Analisis pendapatan dan pengambilan keputusan dalam menentukan tanaman sayuran unggulan di Kecamatan Gisting Kabupaten Tanggamus. Jurnal Ilmu-Ilmu Agribisnis, 1 (2): 98-104. http://jurnal.fp.unila.ac.id/index.php/JIA/ar ticle/view/235/234. [25 Maret 2018].

Mantra IB. 2004. Demografi Umum. Pustaka Pelajar. Yogyakarta.

Mujiburrahmad. 2011. Analisis produktivitas usahatani tomat berbasis agroklimat (kasus dataran medium dan dataran tinggi). Jurnal Sains Riset, 1 (2). http://ejournal.unigha. ac.id/data/Journal\%20\%20SAINS\%20Riset \%20vol\%201\%20no\%202\%204.pdf. [30 Maret 2018].

Pusat Penelitian dan Pengembangan Hortikultura. 2013. Litkajibangdiklatluhrap. http://horti kultura.litbang.pertanian.go.id/. [25 Januari 2015].

Rahim A dan Hastuti DRD. 2008. Ekonomika Pertanian. Penebar Swadaya. Jakarta.

Setjanata. 1983. Perkembangan Penerapan Pola Tanam dan Pola Usahatani dalam Usaha Intensifikasi (Proyek Bimas). Pusat Penelitian dan Pengembangan Tanam. Bogor.

Subagio H dan Manoppo CN. 2011. Hubungan Karakteristik Petani dengan Usahatani Cabai Sebagai Dampak Dari Pembelajaran FMA (Studi Kasus Di Desa Sunju Kecamatan Marawola Provinsi Sulawesi Tengah). https://docs.google. com/viewer?a $=\mathrm{v} \& \mathrm{q}=$ cache:f4eYN9QVXtEJ:jatim.litbang .deptan.go.id/ind/index. Balai Pengkajian Teknologi Pertanian Sulawesi Tengah. [30 Oktober 2017].

Sugiarto. 2003. Teknik Sampling. PT Gramedia Pustaka Utama. Jakarta. 